\title{
ATTENTIONAL LOAD AFFECTS AUTOMATIC EMOTIONAL PROCESSING: EVIDENCE FROM EVENT-RELATED POTENTIALS
}

\author{
Authors: Sonia Doallo, Socorro Rodríguez Holguín and Fernando Cadaveira
}

This is the peer reviewed version of the following article: Doallo S; Rodríguez Holguín S; Cadaveira F. (2006). Attentional load affects automatic emotional processing: evidence from event-related potentials. NeuroReport, 17, 1797-1801. doi: 10.1097/01.wnr.0000246325.51191.39. This article may be used for non-commercial purposes in accordance with Lippincott, Williams \& Wilkins Terms and Conditions for Use of Self-Archived Versions 


\title{
Attentional load affects automatic emotional processing: evidence from event-related potentials
}

\author{
Authors: Sonia Doallo, Socorro Rodríguez Holguín and Fernando Cadaveira \\ Department of Clinical Psychology and Psychobiology, University of Santiago de Compostela, \\ Campus Sur S/N, Santiago de Compostela, Spain
}

Corresponding author: Sonia Doallo, Departamento de Psicoloxia Clínica e Psicobioloxía, Facultade de Psicoloxía, Universidade de Santiago de Compostela, Campus Universitario Sur, E15782, Santiago de Compostela, Galicia, Spain. Tel: + 34981563100 ext.13916; fax: + 34981528 071; e-mail: sdoallo@usc.es

Sponsorship: This study was supported by Spain's Ministerio de Educación y Ciencia (SEJ200401377) and Xunta de Galicia (PGIDT05PXI21101PN). The 1rst author holds a research grant from Deputación de A Coruña. 


\begin{abstract}
One open question on the relation between attention and emotion concerns the automatic processing of emotional visual stimuli outside the focus of attention. This study examined to what extent the emotional processing at unattended locations is modulated by the processing load at attended locations. Event-related potentials were measured to task-irrelevant unpleasant and neutral pictures brie£y presented at peripheral locations while participants performed a visual central task varying in load (low and high load). Unpleasant pictures elicited larger amplitudes of N1-P2 at parietoccipital and occipital sites than that of neutral pictures. This effect was only significant in the low-load condition. Data suggest that brain responses to affective value of task-irrelevant peripheral pictures are modulated by attentional load at fixation.
\end{abstract}

\title{
Keywords
}

Attention, Emotion, Event-related potentials, International Affective Pictures System, Load, P200 


\section{Introduction}

A growing body of research indicates that, in natural environments, attention is mainly determined by the motivational significance of stimuli (natural selective attention or motivated attention) [1]. Behavioral, event-related potentials (ERPs), and neuroimaging studies indicate that attention is preferentially assigned to events with emotional value as compared with neutral ones [2,3], and that the emotional value of stimuli enhances sensory processing in visual cortical areas [4]. It is known that activation of the amygdala modulates cortical activity by increasing visual processing of emotional stimuli [5], either through direct feedback projections to the primary visual cortex [6-8] or indirectly via its projections to frontal areas $[6,8]$.

Accumulating evidence exists that unpleasant stimuli elicit faster and stronger physiological, cognitive, and behavioral responses than pleasant or neutral ones. This phenomenon has been named negativity bias [9]. This attentional bias has been demonstrated from ERP studies [10-12] showing that negative stimuli draw more attention and are faster than positive stimuli.

The controlled emotional processing is well known, but few studies focus on brain mechanisms associated with automatic attention to emotional stimuli [13]. One open question about the relationship between attention and emotion concerns the automatic processing of emotional visual stimuli outside the focus of attention.

Neuroimaging experiments indicate that amygdala may be specialized for fast and automatic detection of events with emotional salience [14], even without awareness [15]. Two processing pathways to amygdala are proposed [16]: a subcortical, collicular-pulvinar-amygdala pathway, involved in the automatic processing and rapid response to emotional stimuli, and the cortico-amygdala pathway [6] mediating object identification.

Two processing pathways to amygdala are proposed [16]: a subcortical, collicular-pulvinar-amygdala pathway, involved in the automatic processing and rapid response to emotional stimuli, and the cortico-amygdala pathway [6] mediating object identification.

Studies of patients with attentional deficits, such as spatial neglect, show that emotionally relevant information from the contralesional hemifield can be processed preattentively, and capture attention more than other stimuli [17]. Recent ERP studies have identified neural correlates of automatic attention to task-irrelevant emotional stimuli $[13,18,19]$.

Despite a growing evidence regarding automatic processing of emotional events occurring outside the focus of attention, the question of the influence of spatial attention on the processing of emotion remains unsolved. ERP evidence shows that cortical stages of emotional processing are strongly 
modulated by focal attention [20], and functional magnetic resonance imaging experiments indicate that the differential brain response to unattended emotional stimuli depends strongly on the attentional load of the ongoing task [8].

In the absence of emotional value, the influence of relevant processing load on the processing of taskirrelevant stimuli is well established by behavioral studies, and ERP and neuroimaging experiments find a decreased response to peripheral distractors in superior visual cortical areas when the attentional load of a relevant task is increased (see [21] for a review). Thus, one question currently debated refers to whether or not this modulatory effect of the attentional load is also present when distractors have emotional value. Recently, functional magnetic resonance imaging evidence supporting the critical role of attentional load in the processing of unattended emotional stimuli has been provided [22].

It is remarkable, however, that there is a lack of ERP studies examining the processing of unattended emotional stimuli under several conditions of attentional load. To gain knowledge on this issue, in the present experiment, the electrophysiological responses to peripheral task-irrelevant neutral and unpleasant pictures were recorded while the attentional load of a central relevant task was varied. Attentional bias to negative emotional pictures was evaluated by analyzing the modulations of the P2 component elicited by task-irrelevant affective pictures. This ERP component is specially sensitive to unpleasant visual stimuli [10,11], and it is also elicited by emotional stimuli presented outside the focus of attention [13].

The aim of this study is to examine to what extent emotional processing at unattended locations is modulated by the processing load at attended locations.

\section{Methods}

\section{Subjects}

Ten female volunteers $(21-30$ years old, mean $=26.4, \mathrm{SD}=2.5)$ were assessed. All were righthanded, had normal or corrected-to-normal vision, and had no history of psychiatric or neurological disorders. Participants gave informed consent.

\section{Stimuli and procedure}

The target stimuli were short $\left(0.6^{\circ} \times 2.3^{\circ}\right)$ or long $\left(0.6^{\circ} \times 3.4^{\circ}\right)$ vertical bars equiprobably flashed for $50 \mathrm{~ms}$ in the center of the display. Vertical bars were sequentially presented, according to a stimulus 1 (S1)-stimulus 2 (S2) paradigm. During the delay period between S1 and S2, 40 negative and 40

\section{Post-print (final draft post-refereeing)}


neutral pictures $\left(8^{\circ} \times 5.7^{\circ}\right)$ taken from the International Affective Pictures System (IAPS) [23] were occassionally presented (negative $\mathrm{P}=0.15$, neutral $\mathrm{P}=0.15$ ) at $5.7^{\circ}$ to the left or to the right from a fixation cross for $50 \mathrm{~ms}$. The two categories differed from each other in the valence rating (2.1 vs. 5.2) and in the arousal rating (7.2 vs. 3.2), on the basis of the normative values of IAPS in the Spanish population [24]. To evaluate the effects of attentional load on the processing of peripheral emotional stimuli, the difficulty of the relevant central task was increased in a different experimental block, in which size discrimination was rendered difficult by reducing the difference between the bars (short bars: $0.6^{\circ} \times 2.3^{\circ}$; long bars: $0.6^{\circ} \times 2.5^{\circ}$ ). Participants were required to maintain eye fixation on the central cross, and to discriminate whether the second bar of the match (S2) was equal or different in size from the first bar (S1), pressing one button with one hand if equal in size and another button with the other hand if different in size, while ignoring the peripheral pictures. The assignment of the response hand was balanced across participants. The interval from S1 onset to distractor onset (SOA) randomly varied from 100 to $1100 \mathrm{~ms}$. SOA between S1 and S2 randomly varied from 1200 to 1500 ms. The intertrial intervals randomly varied from 2000 to $2300 \mathrm{~ms}$. In order to familiarize the participants with the task, the low-load condition was presented in the first place. Each experimental condition consisted of eight trial blocks. The maximum number of trials per block was 125 .

\section{Event-related potential recording and data analysis}

ERPs (bandpass $0.1-50 \mathrm{~Hz}, 500 \mathrm{~Hz} / \mathrm{channel}$ ) were recorded from 16 active electrodes (F3, F4, FC3, $\mathrm{FC} 4, \mathrm{C} 3, \mathrm{C} 4, \mathrm{~T} 5, \mathrm{~T} 6, \mathrm{CP} 3, \mathrm{CP} 4, \mathrm{P} 3, \mathrm{P} 4, \mathrm{PO} 3, \mathrm{PO} 4, \mathrm{O} 1$, and O2), referred to a nasal electrode. Vertical and horizontal eye movements were recorded bipolarly from above and below the left eye and from the outer canthi of both eyes. Impedances were kept below $10 \mathrm{k} \Omega$. Reaction time (RT) and percentage of correct responses were recorded for each trial. Data were collected over epochs from 60 $\mathrm{ms}$ before stimulus to $600 \mathrm{~ms}$ after stimulus. Trials with eye blinks or horizontal eye movements were rejected. For each participant, ERPs elicited by neutral and emotional distractors were averaged (digital bandpass of $0.1-30 \mathrm{~Hz}$ ) separately for each visual field and condition.

Visual inspection of waveforms revealed one positive wave corresponding to the P200 component, about $170 \mathrm{~ms}$ after the picture. It also revealed that the ERP to the distractor stimuli was affected by a sustained negative shift, which extended to a large part of the scalp. For this reason, the amplitude of the P2 component was measured 'peak to peak' relative to the anterior negative peak (N1). Peak amplitudes were measured using latency windows of 110-215 ms for N1 and 160-250 ms for P2. Repeated-measures analyses of variance (ANOVAs) were performed on amplitude values with five within-participant factors: region [frontal (F) / frontocentral (FC) / central (C) /centroparietal (CP) / parietal $(\mathrm{P}) /$ temporal $(\mathrm{T})$ / parietoccipital $(\mathrm{PO})$ / occipital $(\mathrm{O})$ ], hemisphere of recording (left / right), load condition (low / high), valence (neutral / negative), and visual field (left / right). Significance levels were determined using degrees of freedom after applying the Greenhouse-Geisser correction 
when appropriate. Post-hoc comparisons were performed using the Bonferroni adjustment for multiple comparisons.

Repeated-measures ANOVAs including two factors (load, two levels; and distractor, five levels: none / left neutral / right neutral / left emotional / right emotional) were conducted for the RT and accuracy data.

\section{Results}

\section{Behavioral results}

There was a significant effect of load on accuracy $[\mathrm{F}(1,9)=351.622, \mathrm{P}=0.000]$, with a larger percentage of correct responses for low-load than for high-load condition (91.977.9 vs. 63.879.8).

The factor distractor had significant effects on $\mathrm{RT}[\mathrm{F}(4,36)=3.329, \mathrm{P}=0.020]$ : responses to stimuli not preceded by distractor tended to be faster than responses to stimuli preceded by neutral or emotional distractors. These differences were, however, not significant after the Bonferroni adjustment. Separate ANOVAs for each condition showed that the factor distractor only reached statistical significance in the low-load condition $[F(4,36)=2.998, P=0.031]$.

Event-related potential results

There was a significant main effect of the factor region on N1-P2 amplitude $[\mathrm{F}(7,63)=23.285, \mathrm{P}=$ $0.0005, \varepsilon=0.229$ ], with largest amplitudes at parietoccipital (PO vs. $\mathrm{F}: \mathrm{P}=0.011$; $\mathrm{PO}$ vs. FC: $\mathrm{P}=$ 0.018 ; $\mathrm{PO}$ vs. $\mathrm{C}: \mathrm{P}=0.027$; $\mathrm{PO}$ vs. $\mathrm{CP}: \mathrm{P}=0.026$; $\mathrm{PO}$ vs. $\mathrm{P}: \mathrm{P}=0.013)$ and occipital (O vs. $\mathrm{F}: \mathrm{P}=$ 0.004; $\mathrm{O}$ vs. $\mathrm{FC}: \mathrm{P}=0.007$; $\mathrm{O}$ vs. $\mathrm{C}: \mathrm{P}=0.014 ; \mathrm{O}$ vs. $\mathrm{CP}: \mathrm{P}=0.022$ ) locations. There were also significant region $\mathrm{x}$ load $\mathrm{x}$ valence $[\mathrm{F}(7,63)=5.571, \mathrm{P}=0.015, \varepsilon=0.272]$ and region $\mathrm{x}$ hemisphere $\mathrm{x}$ visual field $[\mathrm{F}(7,63)=8.540, \mathrm{P}=0.002, \varepsilon=0.294]$ interactions. Separate analysis for each region revealed that the load $x$ valence interaction persisted for $\mathrm{PO}[\mathrm{F}(1,9)=8.559, \mathrm{P}=0.017]$ and $\mathrm{O}[\mathrm{F}(1,9)$ $=9.764, \mathrm{P}=0.012 \mathrm{]}$ sites (see Figs 1 and 2). Additional analyses for each condition confirm these interactions, showing a main effect of valence only for the low-load condition $[\mathrm{PO}: \mathrm{F}(1,9)=10.879, \mathrm{P}$ $=0.009 ; \mathrm{O}: \mathrm{F}(1,9)=17.776, \mathrm{P}=0.002]$. On the other hand, separate analysis for each region indicated that the hemisphere $x$ visual field interaction also persisted for these posterior locations [PO: $F(1,9)=$ 9.184, $\mathrm{P}=0.014 ; \mathrm{O}: \mathrm{F}(1,9)=5.825, \mathrm{P}=0.039$ ], showing that contralaterally presented stimuli elicited larger amplitudes over the right hemisphere, whereas there were no differences as a function of visual field over the left hemisphere. 


\section{Discussion}

ERPs were used to examine whether (i) unattended negative stimuli capture attention more effectively than neutral stimuli, and (ii) the processing load at attended locations affects to this capture.

The results show that the emotional value of distractor stimuli presented at the periphery of the visual field modulates the amplitude of the N1-P2 component at parietoccipital and occipital locations, with larger amplitudes to emotional than neutral pictures. This affective modulation over posterior regions was only present in the low-load condition, but not in the most demanding task.

P200 has been proposed to reflect an early attentional process, which facilitates a fast detection of biologically significant stimuli, such as events with negative value [10]. This component has been related to the negativity bias [11]. There is also evidence that P2 is associated with an automatic capture of attention by irrelevant emotional stimuli (negative and positive), while attention is focused on another task [13]. The findings in this experiment are also in line with the ERP modulations reported by Delplanque et al. [25] during the processing of IAPS pictures that did not demand an explicit categorization of valence. These authors reported larger P1 (150-165 ms) and P2 (180-213 ms) components to unpleasant than pleasant stimuli over parietoccipital sites. Thus, the present data are consistent with previous ERP studies, supporting the hypothesis that attention is preferentially directed to unpleasant stimuli, resulting in the automatic capture of attention under conditions in which top-down control is focused in a relevant task. The N1-P2 modulations extend these findings revealing that these effects are influenced by the attentional load of the relevant task.

Other studies, however, did not observe effects of valence when emotional facial expressions were presented at unattended locations [20]. Discrepant results may be attributed to noticeable differences between the experimental designs. Whereas Holmes et al. used faces as distractor stimuli, presented simultaneously with the relevant stimuli, here IAPS distractor pictures were presented during the S1S2 interval of a matching task. Although this type of task requires a continuing monitoring of the relevant location (central fixation), the simultaneous presentation of stimuli employed by Holmes et al. probably involves competition for neural resources: it is possible that their task demands more processing resources than the present low-load condition.

With regard to the neural origin of these ERP effects, two neural sources of the P2 component have been proposed by Carretié et al. [13]. They found that the P200 component related to visual attention to previously announced negative stimuli originates in dorsal stream areas, specifically in the visual 
association cortex (posterior middle temporal gyrus), which facilitates a fast reaction to emotional stimuli [10]. More recently, they reported that the dorsal anterior cingulate cortex also contributes to the generation of P2 during automatic attention to emotional stimuli [13].

This study also adds to the evidence that attentional capture by emotional stimuli depends on the availability of attentional resources. Behavioral findings confirmed that the different experimental conditions involved changes in the attentional demands: reaction times revealed that distractors (independently of affective value) presented in the periphery of the visual field capture attention under the low-load condition, but not when attentional load of relevant task was increased. These data, together with the high percentage of errors in the high-load condition, indicate that the attentional focus manipulation was correct. Behavioral performance, however, was not sensitive to the affective value of pictures, one effect that is present in ERP data: the N1-P2 amplitude was larger in response to emotional pictures than neutral pictures under low-load conditions. This result is in agreement with neuroimaging studies, which have shown that responses in the visual cortex to task-irrelevant peripheral stimuli were reduced when the relevant processing load at fixation increased [21].

\section{Conclusion}

This study verifies that unpleasant pictures receive prioritized processing compared with neutral ones when attention is focused on other stimuli. This processing is, however, influenced by the attentional load of the ongoing task, which strongly modulates the automatic response to emotional events. 


\section{References}

1. Lang PJ, Bradley MM, Cuthbert BN. Motivated attention: affect, activation, and action. In: Lang PJ, Simons RF, Balaban M, editors. Attention and orienting. Sensory and motivational processes. Mahwah, NJ: Lawrence Erlbaum Associates; 1997. pp. 97-135.

2. Öhman A, Flykt A, Lundqvist D. Unconscious emotion: evolutionary perspectives, psychophysiological data, and neuropsychological mechanisms. In: Lane RD, Nadel L, editors. Cognitive neuroscience of emotion. New York: Oxford University Press; 2002. pp. 296-327.

3. Schupp HT, Junghöfer M, Weike AI, Hamm AO. Emotional facilitation of sensory processing in the visual cortex. Psychol Sci 2003; 14:7-13.

4. Lang PJ, Bradley MM, Fitzsimmons JR, Cuthbert BN, Scott JD, Moulder B, et al. Emotional arousal and activation of the visual cortex: an fMRI analysis. Psychophysiology 1998; 35:199-210.

5. Morris JS, Friston KJ, Büchel C, Frith CD, Young AW, Calder AJ, et al. A neuromodulatory role for the human amygdala in processing emotional facial expressions. Brain 1998; 121:47-57.

6. Amaral DG, Price JL, Pitkänen A, Carmichael ST. Anatomical organization of the primate amygdaloid complex. In: Anggleton JP, editor. The amygdala: neurobiological aspects of emotion, memory and mental dysfunction. New York: Wiley-Liss; 1992. pp. 1-66.

7. Vuilleumier P, Richardson MP, Armony JL, Driver J, Dolan RJ. Distant influences of amygdala lesion on visual cortical activation during emotional face processing. Nat Neurosci 2004; 7:12711278.

8. Pessoa L, Kastner S, Ungerleider LG. Attentional control of the processing of neutral and emotional stimuli. Cogn Brain Res 2002; 15:31-45.

9. Cacioppo JT, Gardner WL. Emotion. Annu Rev Psychol 1999; 50:191-214.

10. Carretié L, Martín-Loeches M, Hinojosa JA, Mercado F. Emotion and attention interaction studied through event-related potentials. J Cogn Neurosci 2001; 13:1109-1128.

11. Carretie L, Mercado F, Tapia M, Hinojosa JA. Emotion, attention, and the 'negativity bias', studied through event-related potentials. Int J Psychophysiol 2001; 41:75-85.

12. Smith NK, Cacioppo JT, Larsen JT, Chartrand TL. May I have your attention, please: electrocortical responses to positive and negative stimuli. Neuropsychologia 2003; 41:171-183. 
13. Carretié L, Hinojosa JA, Martín-Loeches M, Mercado F, Tapia M. Automatic attention to emotional stimuli: neural correlates. Hum Brain Mapp 2004; 22:290-299.

14. Vuilleumier P, Armony JL, Driver J, Dolan RJ. Effects of attention and emotion on face processing in the human brain: an event-related fMRI study. Neuron 2001; 30:829-841.

15. Öhman A. Automaticity and the amygdala: nonconscious responses to emotional faces. Curr Direct Psychol Sci 2002; 11:62-66.

16. LeDoux JE. The emotional brain. Nueva York: Simon \& Schuster; 1996.

17. Vuilleumier P. Facial expression and selective attention. Curr Opin Psychiatry 2002; 15:291-300.

18. Carretié L, Hinojosa JA, Mercado F, Tapia M. Cortical response to subjectively unconscious danger. Neuroimage 2005; 24:615-623.

19. Schupp HT, Junghöfer M, Weike AI, Hamm AO. Attention and emotion: an ERP analysis of facilitated emotional stimulus processing. Neuroreport 2003; 14:1107-1110.

20. Holmes A, Vuilleumier P, Eimer M. The processing of emotional facial expression is gated by spatial attention: evidence from event-related brain potentials. Cogn Brain Res 2003; 16:174-184.

21. Lavie N. Distracted and confused?: selective attention under load. Trend Cogn Sci 2005; 9:75-82.

22. Pessoa L, Padmala S, Morland T. Fate of unattended fearful faces in the amygdala is determined by both attentional resources and cognitive modulation. Neuroimage 2005; 28:249-255.

23. Lang PJ, Bradley MM, Cuthbert BN. International affective picture system (IAPS): Instruction manual and affective ratings 1999. The Center for Research in Psychophysiology, University of Florida.

24. Moltó J, Montañés S, Poy R, Segarra P, Pastor MC, Tormo MP, et al. Un nuevo método para el estudio experimental de las emociones: el International Affective Picture System (IAPS). Adaptación española [A new method for the experimental study of emotions: The International Affective Picture System (IAPS)] [in Spanish]. Rev Psicol Gen Aplicada 1999; 52:55-87.

25. Delplanque S, Lavoie ME, Hot P, Silvert L, Sequeira H. Modulation of cognitive processing by emotional valence studied through event-related potentials in humans. Neurosci Lett 2004; 356:1-4. 


\section{Figures}

Low-load condition

Left visual field
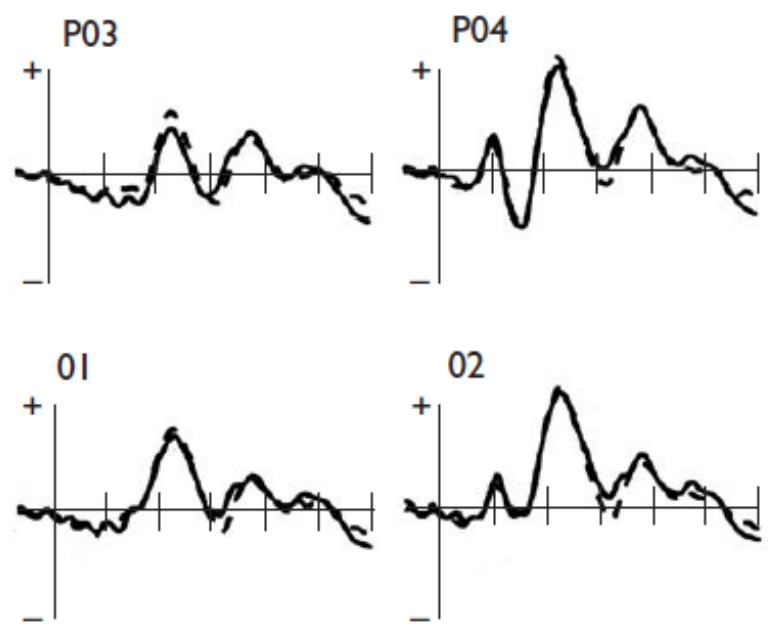

Unpleasant

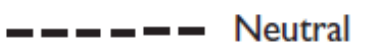

Right visual field
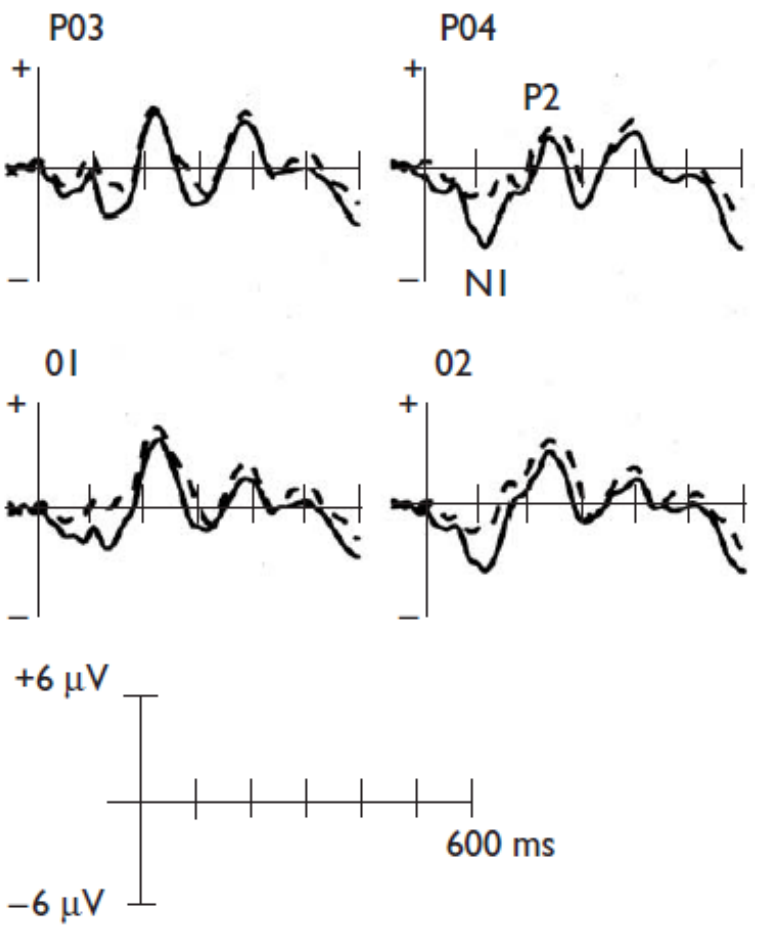

Figure 1. Low-load condition: grand-averaged event-related potential event-related potentials to unpleasant and neutral task-irrelevant pictures presented in the left and right visual fields at parietoccipital (PO) and occipital (O) regions. 
High-load condition

Left visual field

Right visual field
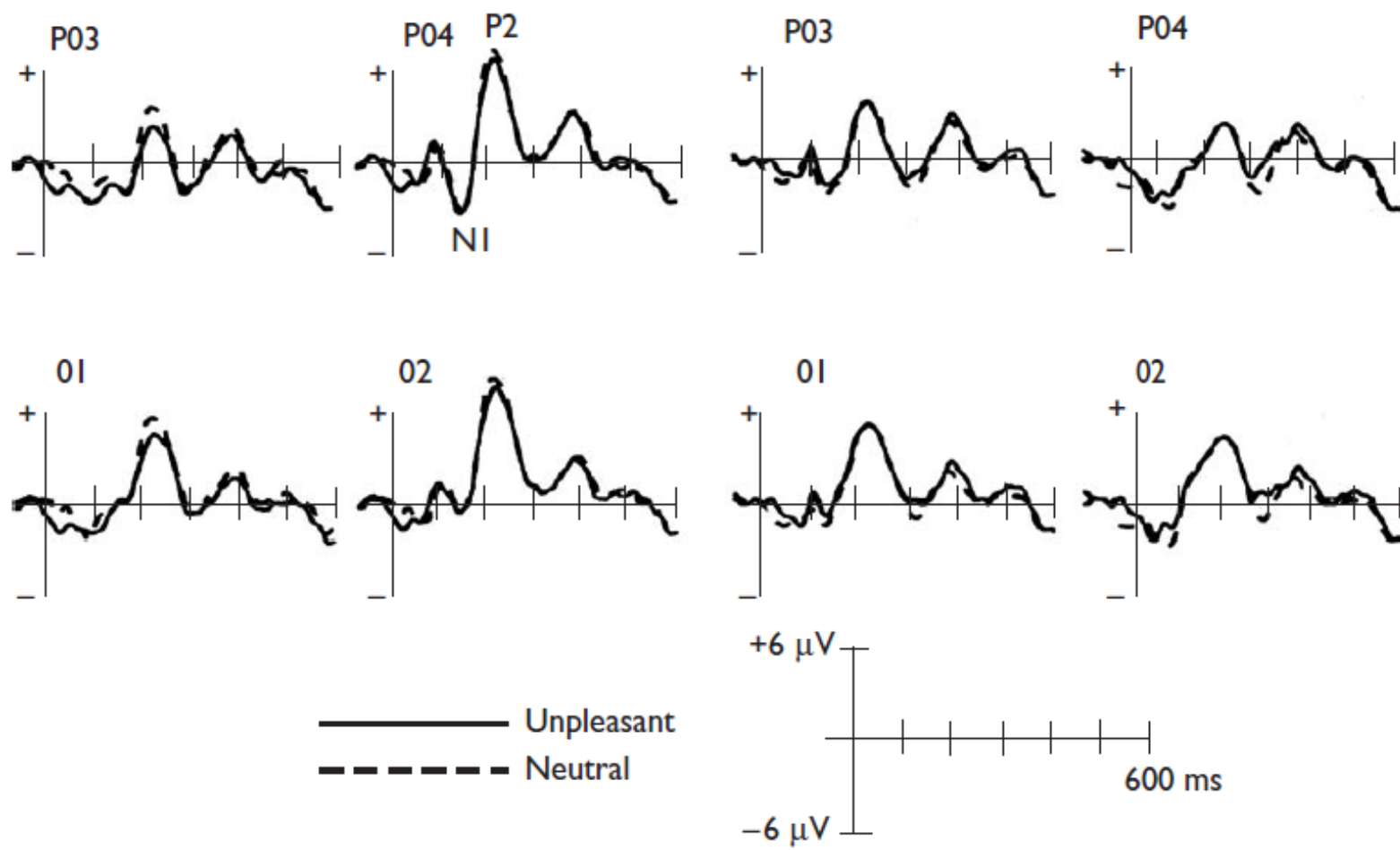

Figure 2. High-load condition: Grand-averaged event-related potentials to unpleasant and neutral task-irrelevant pictures presented in the left and right visual fields at parietoccipital (PO) and occipital (O) regions. 